\title{
Different techniques for Analysis of Aspirin, Caffeine, Diclofenac Sodium and Paracetamol: Review Article
}

\author{
Mahmoud M. Sebaiy ${ }^{1 *}$, Sobhy M. El-Adl ${ }^{1}$, and Amr A. Mattar ${ }^{1 \& 2}$ \\ ${ }^{1}$ Medicinal Chemistry Department, Faculty of Pharmacy, Zagazig University, Zagazig, 44519, Egypt. \\ ${ }^{2}$ Pharmaceutical Medicinal Chemistry Department, Faculty of Pharmacy, Egyptian Russian University, Badr City, Cairo 11829, Egypt. \\ *Authorcorrespondence: E-mail: mmsebaiy@zu.edu.eg; sebaiym@gmail.com.Tel: 01062780060. Fax: 0552303266 \\ Submitted: 27 April 2020 \\ Approved: 11 May 2020 \\ Published: 14 May 2020 \\ How to cite this article: Sebaiy MM, El-Adl SM, Mattar AA. Different techniques for Analysis of Aspirin, Caffeine, Diclofenac Sodium and \\ Paracetamol: Review Article. G Med Sci. 2020; 1(1): 013-031. https://www.doi.org/10.46766/thegms.pharma.20042701 \\ Copyright: () 2020 Mahmoud MS. This is an open access article distributed under the Creative Commons Attribution License, which permits unre- \\ stricted use, distribution, and reproduction in any medium, provided the original work is properly cited.
}

\section{ABSTRACT}

Early treatment of pain is of a great importance as unrelieved pain can have profound psychological effects on the patient, and acute pain that is poorly managed initially can degenerate into chronic pain, which may prove to be much more difficult to treat. It is important to assess and treat the mental and emotional aspects of the pain as well as its physical aspects. Although drug therapy is a mainstay of pain treatment, physical methods such as physiotherapy (including massage and the application of heat and cold), surgery, and drug monitoring are also very valuable. In this review article, we will shed the light on different ways of some analgesic drugs monitoring and analysis using different techniques in addition to the most recommended combinations of our cited drugs for pain relief.

\section{INTRODUCTION}

According to British National Formulary: Analgesics can be divided into three broad classes: non-opioid (e.g. paracetamol and Nonsteroidal anti-inflammatory drugs), opioids (e.g. codeine phosphate 'weak' and morphine 'strong') and adjuvant (e.g. antidepressants and antiepileptics)[1].

\section{Non-opioid Analgesics[2]: \\ Nonsteroidal anti-inflammatory drugs(NSAID)}

Nonsteroidal anti-inflammatory drugs (NSAIDs) are a group of structurally unrelated organic acids that have analgesic, anti-inflammatory, and antipyretic properties. NSAIDs are inhibitors of the enzyme cyclooxygenase, and so directly inhibit the biosynthesis of prostaglandins and thromboxanes from arachidonic acid. There are 2 forms of cyclooxygenase (COX),COX-1, which is the constitutive form of the enzyme, andCOX-2, which is the form induced in the presence of inflammation.Inhibition of COX-2 is therefore thought to beresponsible for at least some of the analgesic, anti-inflammatory, and antipyretic properties of NSAIDs whereas inhibition of COX-1 is thought to produce some of their toxic effects, particularly those on the gastrointestinal tract. Most of the NSAIDs currently available for clinical use inhibit both COX-1 and COX-2, although selective COX-2 inhibitors such as celecoxib are now available. NSAIDs 
are used for the relief of mild to moderate pain, minor febrile conditions, and for acute and chronic inflammatory disorders such as osteoarthritis, rheumatoid arthritis, juvenile idiopathic arthritis, and ankylosing spondylitis. Indomethacin and some other NSAIDs are used to close patent ductus arteriosus in premature neonates. Some NSAIDs are applied topically for the relief of muscular and rheumatic pain, and some are used in ophthalmic preparations for ocular inflammatory disorders. Aspirin is considered to be an NSAID, although it also has other properties.

\section{Aspirin and other salicylates}

Aspirin and other salicylates have analgesic, anti-inflammatory, and antipyretic properties. Like other NSAIDs, they are inhibitors of the enzyme cyclooxygenase; however, aspirin (though not the non-acetylated salicylates) irreversibly acetylates the enzyme whereas other NSAIDs compete with arachidonic acid for the active site. Salicylates are used for the relief of mild to moderate pain, minor febrile conditions, and for acute and chronic inflammatory disorders such as osteoarthritis, rheumatoid arthritis, juvenile idiopathic arthritis, and ankylosing spondylitis. Some salicylates are applied topically in rubefacient preparations for the relief of muscular and rheumatic pain. Aspirin also inhibits platelet aggregation and is used in cardiovascular disorders. Non-acetylated salicylates do not have antiplatelet activity.

\section{Paracetamol and other para-aminophenols}

Paracetamol is the principal para-aminophenol derivative in use. Acetanilide and phenacetin have generally been replaced by safer analgesics. Paracetamol has analgesic and antipyretic properties and weak anti-inflammatory activity. The mechanism of analgesic action remains to be fully elucidated, but may be due to inhibition of prostaglandin synthesis both centrally and peripherally. Paracetamol is used for the relief of mild to moderate pain and minor febrile conditions.

\section{Opioid Analgesics[2]:}

Opioid analgesics include the opium alkaloids morphine and codeine and their derivatives as well as synthetic substances with agonist, partial agonist, or mixed agonist and antagonist activity at opioid receptors. The term opiate analgesics refers only to those opioids derived from opium, or their semisynthetic congeners. The term narcotic analgesics has legal connotations and is no longer used pharmacologically or clinically. Most opioids are used as analgesics, and morphine is the standard against which all other opioid analgesics are compared. Opioids such as codeine or dextropropoxyphene are used in the treatment of less severe pain, and are often combined with non-opioid analgesics such as aspirin, other NSAIDs, or paracetamol. More potent opioids such as morphine are used in severe acute and chronic pain, including cancer pain. Some opioids such as codeine, morphine, and diamorphine are also used as antitussives, althoughthe latter two are usually reserved for use in terminal lung disease. Some opioid analgesics such as fentanyl and its congeners are used mainly as adjuncts to anaesthesia; some of these may also be used in higher dosesas the sole anaesthetic drug. Opioids can produce physical dependence and withdrawal symptoms if suddenly stopped. They are also subject to abuse.

On the other hand, caffeine has been used with the aim of enhancing the effects of non-opioid and opioid analgesics but is of debatable benefit. There are similar doubts about whether caffeine enhances the effect of ergotamine in the treatment of migraine; it may also add to gastrointestinal adverse effects and in large doses can itself cause headache.

\section{Aspirin (Acetylsalicylic acid)}<smiles>CC(=O)Oc1ccccc1C(=O)O</smiles>

Molecular Formula: $\mathrm{C}_{9} \mathrm{H}_{8} \mathrm{O}_{4}$.

Chemical name: 2-(Acetyloxy)benzoic acid.

M.Wt: 180.2.

Mode of Action and uses: Salicylate; non-selective cyclo-oxygenase inhibitor; antipyretic; analgesic; anti-inflammatory.

\section{Characters:}

Appearance: White or almost white, crystalline powder or colourless crystals.

Solubility: Slightly soluble in water, freely soluble in ethanol (96 per cent).

\section{Melting point: About $143^{\circ} \mathrm{C}$.}

Storage: In an airtight container.

\section{Methods of determination:}

\section{Pharmacopeial methods:}

\section{British pharmacopeia[3]:}

In a flask with a ground-glass stopper, dissolve $1.000 \mathrm{~g}$ in $10 \mathrm{ml}$ of ethanol ( 96 per cent) R.Add $50.0 \mathrm{ml}$ of 0.5 
M sodium hydroxide. Close the flask and allow to stand for $1 \mathrm{~h}$. Using $0.2 \mathrm{ml}$ of phenolphthalein solution $\mathrm{R}$ as indicator, titrate with $0.5 \mathrm{M}$ hydrochloric acid. Carry out a blank titration.

$11 \mathrm{ml}$ of $0.5 \mathrm{M}$ sodium hydroxide is equivalent to 45.04 mg of $\mathrm{C}_{9} \mathrm{H}_{8} \mathrm{O}_{4}$

\section{United States pharmacopeia[4]:}

Place about $1.5 \mathrm{~g}$ of Aspirin, accurately weighed, in a flask, add $50 \mathrm{ml}$ of $0.5 \mathrm{~N}$ Sodium hydroxide VS, and boil the mixture gently for 10 minutes. Add phenolphthalein TS, and titrate the excess sodium hydroxide with $0.5 \mathrm{~N}$ sulfuric acid VS. Perform a blank determination.

Each $\mathrm{mL}$ of $0.5 \mathrm{~N}$ sodium hydroxide is equivalent to $45.04 \mathrm{mg}$ of $\mathrm{C}_{9} \mathrm{H}_{8} \mathrm{O}_{4}$.

\section{Other methods of determination:}

\subsection{Spectrophotometric methods:}

Aspirin was determined by dilution with anhydrous ethanol and volumes of aspirin samples were micropipetted directly into the cuvette as required by an auto-controlled microstirrerin which a blank of anhydrous ethanol was used as reference[5].

Folin-Ciocalteu phenol reagent was used for determination of aspirin and salicylic acid concentrations in human plasma[6].

A method for determination of aspirin and salicylic acid in aspirin tablets was determined by second derivative spectroscopy by using ethanol containing $1 \%$ citric acid as a solvent[7].

Simultaneous analysis of aspirin and salicyclic acid in pharmaceutical tablet preparations was performed by two multicomponent UV-spectrophotometric methods utilizing principal component regression and classical least square algorithm and an assay procedure based on second derivative spectroscopy was developed[8].

Simultaneous determination of methocarbamol and aspirin binary mixture in their combined tablets by derivative and ratio derivative spectrophotometry was reported[9].

The estimation of paracetamol, aspirin, ibuprofen, codeine and caffeine drug percentages in standard and some formulated commercial dosage by using a UV-Spectroscopic method was developed in which the absorption maxima of drugs were found to be $(244.8 \mathrm{~nm}, 238 \mathrm{~nm}$, $220.6 \mathrm{~nm}, 278 \mathrm{~nm}$ and $272.6 \mathrm{~nm}$ ) respectively, by using deionized water: acetonitrile $(90: 10 \mathrm{v} / \mathrm{v})$ as solvent[10].

The estimation of paracetamol and aspirin in mixtures was estimated by non-aqueous potentiometric titrimetry or by ultraviolet spectrophotometry[11].

\subsection{Chromatographic methods:}

Chromatographic method for the simultaneous determination of aspirin, caffeine, and acetaminophen by using a duplex column having aqueous solutions of sodium bicarbonate and sulfuric acid as immobile phases on a Celite support was determined[12].

Aspirin can be extracted with dichloromethane using mephenytoin as an internal standard, the solvent was then evaporated under reduced pressure then the residue reconstituted and analyzed by high performance liquid chromatography (HPLC) [13].

In rat whole blood, aspirin and salicylic acid were extracted from acidified whole blood into a $50 / 50 \mathrm{v} / \mathrm{v}$ ethy 1 acetate/butylchloride organic solvent system containing internal standard then organic extract under partial vacuum was evaporated, the dried residue was reconstituted with mobile phase and separation by ion suppression reverse phase on a $5 \mu \mathrm{m}$ octyldecasil and column with detection by UV absorbance at $280 \mathrm{~nm}$ was performed[14].

Determination of aspirin and slicylic acid in human plasma by column-switching liquid chromatography using on-line solid-phase extraction by using C18 extraction column and a mixture of water-methanol- acetonitrile-orthophosphoric acid as a mobile phase was reported[15].

Simultaneous determination of aspirin and isosorbide 5-mononitrate in formulation by reversed phase high pressure liquid chromatography by using a Thermo Quest C18 column was performed in which a mixture of water-methanol (water $\mathrm{pH}$ adjusted to 3.4 using dilute orthophosphoric acid) was used throughapplying chlorzoxazone as internal standard[16].

Sensitive estimation of aspirin and its three metabolites in rat plasma by LC-UV using on-line solid-phase extraction with methylcellulose-immobilized anion-exchange restricted access media was reported[17].

An Agilent Zorbax XDB column and a mixture of $0.2 \%$ orthophosphoric acid, methanol, and acetonitrile as a mobile phase was used for simultaneous determination of aspirin and esomeprazole magnesium in combined tablets by ultra performance liquid chromatography (UPLC) [18].

Sinhaet al,[19]developed a validated stability indicating HPTLC method for determination of aspirin and clopidogrel in combined dosage form by using TLC aluminum plates precoated with silica gel $60 \mathrm{~F} 254$ as the stationary phase and carbon tetrachloride-acetone $(6: 2.4, \mathrm{v} / \mathrm{v})$ as the solvent system.

A method for determination of aspirin and its major metabolites in human urine by gas chromatography-mass 
spectrometry by extraction through solid phase C18 cartridges was developed[20].

\subsection{Miscellaneous methods:}

Fluorescent determination of aspirin by using core-shell cadmium telluride quantum dot-imprinted polymers was developed[21].

Electrochemical sensor for the simultaneous determination of caffeine and aspirin in human urine samples by using edge plane pyrolytic graphite electrode was developed[22].

A highly sensitive voltammetric sensor method was developed for determination of aspirin and caffeine in which the sensor was fabricated on a glassy carbon electrode modified with a composite film of poly (4-vinylpyridine) and multiwall carbon nanotubes[23].

Aspirin and omeprazole were determined by using nanomagnetite/glutamine/carbon based electrochemical sensor in presence of sodium dodecyl sulfate[24].

\section{Caffeine}<smiles>Cn1c(=O)c2c(ncn2C)n(C)c1=O</smiles>

\section{Molecular Formula: $\mathrm{C}_{8} \mathrm{H}_{10} \mathrm{~N}_{4} \mathrm{O}_{2}$.}

Chemical name: 1,3,7-Trimethyl-3,7-dihydro- $1 H$ purine-2,6-dione.

\section{M.Wt: 194.2.}

Mode of Action and uses: Central nervous system stimulant.

\section{Characters:}

Appearance: White or almost white, crystalline powder or silky, white or almost white, crystals.

Solubility: SSparingly soluble in water, freely soluble in boiling water, slightly soluble in ethanol (96 percent). It dissolves in concentrated solutions of alkali benzoates or salicylates.

Melting point: $234^{\circ} \mathrm{C}$ to $239^{\circ} \mathrm{C}$.

\section{Methods of determination:}

\section{Pharmacopeial methods:}

\section{British pharmacopeia [3]:}

Dissolve $0.170 \mathrm{~g}$ with heating in $5 \mathrm{ml}$ of anhydrous acetic acid $R$. Allow to cool, add $10 \mathrm{ml}$ of acetic anhydride $R$ and $20 \mathrm{ml}$ of toluene $R$. Titrate with $0.1 \mathrm{M}$ perchloric acid, determining the end-point potentiometrically.

$1 \mathrm{ml}$ of $0.1 \mathrm{M}$ perchloric acid is equivalent to $19.42 \mathrm{mg}$ of $\mathrm{C}_{8} \mathrm{H}_{10} \mathrm{~N}_{4} \mathrm{O}_{2}$.

\section{United States pharmacopeia [4]:}

Method: Chromatographic

Mode: LC

\section{Detection at UV $275 \mathrm{~nm}$}

Collumn: 4.6-mm x 15-cm column $\mathrm{C}_{18}$

Flow rate: $1 \mathrm{~mL} / \mathrm{min}$

Injection size: $10 \mu \mathrm{L}$

\section{Other Methods of determination:}

\subsection{Spectrophotometric methods:}

Paracetamol, caffeine and propyphenazone were determined by means of a single flow-through UV multiparameter sensor (a multiparameter-responding flow-through system with solid phase UV spectrophotometric detection (a multiparameter optosensor))[25].

Two methods : Spectroscopic derivative and reduction of $\mathrm{Fe}^{3+}$ to $\mathrm{Fe}^{2+}$ by paracetamol, the resulting $\mathrm{Fe}^{2+}$ reacts with 1,10-phenanthroline to give a soluble orange-red complex in acetic acid medium were used for determination of aspirin and caffeine in their tablet formulation[26].

Simultaneous kinetic determination of paracetamol and caffeine by H-point standard addition method based on difference in the rate of oxidation of these compounds with $\mathrm{Cu}(\mathrm{II})$-neocuproine system and formation of $\mathrm{Cu}(\mathrm{I})-$ neocuproine complex was reported[27].

A simple, specific, accurate and precise spectrophotometric method was settled for simultaneous determination of paracetamol and caffeine in pure form and in their pharmaceutical formulation commercially known as Panadol Extra $^{\circledR}$. H-Point assay has been used in simultaneous determination of both drugs without prior separation[28]. 
Simultaneous spectrophotometric determination of paracetamol and caffeine in tablet formulation was reported using simultaneous equation method and Q-absorbance equation at isobestic point[29].

Simultaneous determination of paracetamol and caffeine by flow injection solid phase spectrometry using $\mathrm{C}_{18}$ silica gel as a sensing support was determined[30].

Aspirin, paracetamol, caffeine, and chlorpheniramine were determined from commercial pharmaceutical products using principal component regression (PCR) and partial-least squares (PLS) regression[31].

Principal component regression (PCR), partial least squares (PLS) and artificial neural networks (ANN) were usedin the spectrometric multi- component assay of any drug containing paracetamol and caffeine[32].

Green coffee was extracted with $70 \%$ ethanol aqueous solution; then the solution was analyzed by spectroscopy in which caffeine and chlorogenic acids were analyzed[33].

Caffeine content was determined in cola, coffee and tea by second and third order derivative spectrophotometry[34].

Development of HPLC and UV/Vis spectrophotometric methods for determination of caffeine content in tea and instant coffee brands found in the Kenyan market was developed[35].

Sonali S. Bharateand Sandip B. Bharate,[36]developed spectrophotometric and chromatographic assay for determination of acetylsalicylic acid and caffeine in bulk and commercial tablets.

\subsection{Chromatographic methods:}

Paracetamol, caffeine and dipyrone were separated and determined using a $\mu$-Bondapack $\mathrm{C}_{8}$ column by isocratic elution with a flow rate of $1 \mathrm{ml} / \mathrm{min}$. The mobile phase composition was $0.01 \mathrm{M} \mathrm{KH}_{2} \mathrm{PO}_{4}$ - methanol - acetonitrile - isopropyl alcohol (420: 20: 30: 30, v/v/v/v) and spectrophotometric detection was carried out at $215 \mathrm{~nm}$ [37].

Chromatographic method was developed for the simultaneous determination of paracetamol and caffeine in tablet formulation in which the mobile phase consisted ofmethanol-buffer $(70: 30, \mathrm{v} / \mathrm{v})$ ratio. The buffer consists of equal volume of $0.01 \mathrm{M}$ ortho phosphoric acid and 0.01 Mmonobasic sodium phosphate, $\mathrm{pH}$ adjusted to $(4.5 \pm 0.2)$ with orthophosphoric acid. The column used was Zorbax, $\mathrm{C}_{18}$ Column with flow rate of $1 \mathrm{ml} / \mathrm{min}$ using photodiode array detection at $254 \mathrm{~nm}$ [38].

Dewaniet al,[39] developed a method for determination of phenylepherine, paracetamol, caffeine and chlorpheni- ramine in bulk and marketed formulation in which they used a reversed-phase $\mathrm{C}_{18}$ column with mobile phase consisting of acetonitrile, methanol and $10 \mathrm{Mm}$ phosphate buffer (16:22:62,v/v/v) (pH of buffer $2.5 \pm 0.02$, adjusted with ortho phosphoric acid). The flow rate was $1.0 \mathrm{ml} /$ min and eluents were determined at $280 \mathrm{~nm}$.

A reversed phase high performance liquid chromatography (RP-HPLC) method was successfully developed for the simultaneous determination of quaternary mixture consisting of chlorpheniramine maleate, phenylephrine hydrochloride, paracetamol and caffeine in pharmaceutical preparation using an Inertsil ODS $\mathrm{C}_{18}$ column using $0.05 \mathrm{M}$ dibasic phosphate buffer: acetonitrile $(93: 07 ; \mathrm{v} / \mathrm{v})$ as the mobile phase. The flow rate of the mobile phase was adjusted to $1.5 \mathrm{ml} / \mathrm{min}[40]$.

RP-HPLC method was developed for the simultaneous estimation of acetaminophen and caffeine by using $\mathrm{RP}_{18}$ Column, flow rate $1 \mathrm{ml} / \mathrm{min}$ and a mobile phase of methanol -distilled water $(30: 70, \mathrm{v} / \mathrm{v})[41]$.

Simultaneous determination of caffeine, paracetamol and ibuprofen in pharmaceutical formulations by high-performance liquid chromatography with UV detection and by capillary electrophoresis with conductivity detection was described[42].

Determination of paracetamol, propyphenazone and caffeine in pharmaceutical formulations by HPLC was performed on a Gracesmart $\mathrm{C}_{18}$ column using the mixture of water and 2-propanol in the ratio of 80:20, v/v as mobile phase. The $\mathrm{pH}$ of aqueous phase was adjusted to 3 with $1 \%$ o-phosphoric acid and a flow rate was maintained at $1.5 \mathrm{ml} / \mathrm{min}[43]$.

Chromatographic determination of acetaminophen and caffeine was performed on a $\mathrm{C}_{18}$ column using a $0.01 \mathrm{M}$ $\mathrm{KH}_{2} \mathrm{SO}_{4}$ and acetonitrile as mobile phase $(85: 15, \mathrm{v} / \mathrm{v})$ at a flow rate of $1 \mathrm{ml} / \mathrm{min}$ with UV detection at $265 \mathrm{~nm}$ [44].

Caffeine and vitamin B6 were estimated in energy drinks by HPLC using Phenomenex $\mathrm{C}_{18}$ column in which the HPLC was eluted with an isocratic solution of phosphate buffer $(50 \mathrm{mM}, \mathrm{pH} 3.0)$ and methanol $(60: 40, \mathrm{v} / \mathrm{v})$ at a flow rate of $1.0 \mathrm{~mL} / \mathrm{min}[45]$.

The chromatographic separation of caffeine and some drugs was achieved using a Waters Acquity UPLC $\mathrm{C}_{18}$ column. The mobile phase consisted of acetonitrile and water (containing $0.1 \%$ formic acid) $(15: 85, \mathrm{v} / \mathrm{v})$. The triple quadrupole mass spectrometric detection was operated by positive electrospray ionization. Phenacetin was chosen as internal standard. Plasma samples were extracted with dichloromethane-butanol $(10: 1, \mathrm{v} / \mathrm{v})$ [46].

The method of Axelrod and Reichenthal for the determination of caffeine in serum and urine was modified by J.I. Routh et al[47]. 
Determination and characterization of caffeine in tea, coffee and soft drinks by solid phase extraction and high performance liquid chromatography (SPE-HPLC) was applied. $50 \mathrm{~m} \mathrm{M} \mathrm{KH}_{2} \mathrm{PO}_{4}(\mathrm{pH}=2)$, acetonitrile and methanol (40:8:2) was used as solvent as well as mobile phase[48].

Estimation of caffeine content in tea and Matétea by using different methods through extraction with chloroform, micro method with lead-acetate and high performance liquid chromatography method[49].

Assay of caffeine content in non-alcoholic beverages and energy drinks through HPLC-UV method using Supelco HS $\mathrm{C}_{18}$ column, mobile phase $(80: 20, \mathrm{v} / \mathrm{v})$ of methanol: water and aflow rate of $1.5 \mathrm{~mL} / \mathrm{min}$ was performed[50].

A microextraction method, followed by high-performance liquid chromatography was developed for the determination of caffeine in different tea and energy drink samples[51].

Assay of caffeine content of Bale coffee was carried out using HPLC analysis in which the collected samples were objected to liquid-liquid extraction using dichloromethane[52].

RP-HPLC method was carried out for the simultaneous determination of orphenadrine citrate, caffeine and aspirin in presence of their impurities[53].

RP-HPLC method has been developed and validated for the simultaneous estimation of aspirin, caffeine and orphenadrine citrate. The chromatographic separation was achieved with methanol: phosphate buffer (pH 3) in the ratio of $65: 35, \mathrm{v} / \mathrm{v}$ as mobile phase, ACCLAIMTM 120 $\mathrm{C}_{18}$ column, at a flow rate of $1 \mathrm{ml} / \mathrm{m}$ using isocratic elution[54].

Determination of caffeine, theobromine and theophylline in Mate beer and Mate soft drinks by HPTLC-UV on LiChrospher silica gel plates with fluorescence indicator and acetone/toluene/chloroform (4:3:3, v/v/v) as the mobile phase was estimated[55].

Determination of caffeine content in tea powder by colorimetric method was reported in which tea powder was extracted with chloroform through gentle warming in water bath. The preparative TLC was carried out by using silical gel $G$ as stationary phase and chloroform; acetone (9:1) as a mobile phase. $10 \% \mathrm{w} / \mathrm{v}$ solution of phosphomolybdic acid in water was added and boiled for few minutes[56].

A TLC spectrodensitometric method in which silica gel plate using ethyl acetate: acetone: methanol: triethylamine (6:3:1:0.2, v/v/v) as mobile phase was used for determination of aspirin, caffeine and orphenadrine Citrate[57].

\subsection{Miscellaneous methods:}

Voltammetric sensor based on boron-doped diamond electrode for simultaneous determination of paracetamol, caffeine and aspirin in pharmaceutical formulations employing cyclic voltammetry and square-wave adsorptive stripping voltammetry was reported[58].

An electrochemical sensor based on the electrocatalytic activity of graphene (Gr) for sensitive detection of caffeine was presented. The electrochemical behaviors of caffeine on Nafion-Gr modified glassy carbon electrode were investigated by cyclic voltammetry and differential pulse voltammetry[59].

Comparison of capillary electrophoresis and high performance liquid chromatography methods for caffeine determination in decaffeinated coffee was presented[60].

\section{Diclofenac Sodium}<smiles>NC(=O)Cc1ccccc1Nc1c(Cl)cccc1Cl</smiles>

Molecular Formula: $\mathrm{C}_{14} \mathrm{H}_{10} \mathrm{C}_{12} \mathrm{NNaO}_{2}$.

Chemical name: Sodium 2-[(2,6-dichlorophenyl) amino] phenyl] acetate.

M.wt: 318.1.

Mode of Action and uses: Cyclo-oxygenase inhibitor; analgesic; anti-inflammatory.

\section{Characters:}

Appearance: White or slightly yellowish, slightly hygroscopic, crystalline powder.

Solubility: Sparingly soluble in water, freely soluble in methanol, soluble in ethanol (96 per cent), slightly soluble in acetone.

Melting point: About $280^{\circ} \mathrm{C}$, with decomposition.

Storage: In an airtight container, protected from light.

\section{Methods of determination:}

\section{Pharmacopeial methods:}

\section{British pharmacopeia[3]:}

Dissolve $0.250 \mathrm{~g}$ in $30 \mathrm{ml}$ of anhydrous acetic acid R. Ti- 
trate with $0.1 \mathrm{M}$ perchloric acid, determining the endpoint potentiometrically.

$1 \mathrm{ml}$ of 0.1 M perchloric acid is equivalent to $31.81 \mathrm{mg}$ of $\mathrm{C}_{14} \mathrm{H}_{10} \mathrm{C}_{12} \mathrm{NNaO}_{2}$.

\section{United States pharmacopeia[4]:}

\section{Method: Titrimetric}

Sample solution: Dissolve about $450 \mathrm{mg}$ of Diclofenac Sodium in $25 \mathrm{~mL}$ of glacial acetic acid.

Analysis: Titrate with Titrant ( $0.1 \mathrm{~N}$ perchloric acid), determining the endpoint potentiometrically. Perform a blank determination, and make any necessary correction. Each $\mathrm{ml}$ of $0.1 \mathrm{~N}$ perchloric acid is equivalent to $31.81 \mathrm{mg}$ of diclofenac sodium.

\section{Other Methods of determination}

\subsection{Spectrophotometric methods:}

Diclofenac sodium reacts with an excess of methylene blue in the $\mathrm{pH}$ range 9.2-9.4, to form a chloroform-extractable blue ion-association complex for spectrophotometric determination of diclofenac sodium[61].

Diclofenac reduces iron(III) to iron(II) when heated in aqueous solution in which the ferrous ions produced can react with 2,2'-bipyridine to form a complex having a maximum absorbance at $520 \mathrm{~nm}[62]$.

Diclofenac sodium can form colored compound with Ce(IV)-3-methyl-2-benzothiazolinone hydrazone hydrochloride in $\mathrm{H} 2 \mathrm{SO} 4$ medium to be assayed using flow-injection spectrophotometric method[63].

The reaction of diclofenac or mefenamic acid with potassium ferricyanide in a sodium hydroxide medium and the absorbance of the orange products obtained is measured at $455 \mathrm{~nm}$ for diclofenac and at $465 \mathrm{~nm}$ for mefenamic acid by two flow-injection spectrophotometric methods[64].

The oxidation of diclofenac sodium or piroxicam by iron(III) in the presence of o-phenanthroline in acetate buffer solution ( $\mathrm{pH} 4.4-4.8$ ) to form a ferroin complex is measured at $510 \mathrm{~nm}[65]$.

A yellowish compound with maximum absorbance at 380 $\mathrm{nm}$ is formed upon the reaction of diclofenac sodium with concentrated nitric acid ( $63 \% \mathrm{w} / \mathrm{v})$ and can be measured spectrophotometrically[66].

Partial least square (PLS) chemometric method can be used for determination of benzyl alcohol and diclofenac in pharmaceutical formulations[67].
Mahmoud Sebaiy and Amr Mattar[68] developed an accurate and precise spectrophotometric method for simultaneous determination of paracetamol and diclofenac sodium in pure form and in Diclocin $®$ tablets. H-Point assay has been used in simultaneous determination of both drugs without prior separation.

Direct spectrophotometric evaluation of diclofenac sodium in tablets, serum and urine samples by using aqueous medium without using a chemical reagent was developed[69].

Sodium 1,2- naphthoquine- 4-sulfonate reagent in an alkaline medium was used for estimation of diclofenac sodium by forming an orange-colored product which has a maximum absorbance at $456 \mathrm{~nm}$ [70].

Spectrophotometric methods including simultaneous equation method, absorption ratio method and dual wavelength method were used for determination of paracetamol and diclofenac sodium by application of hydrotropic solubilization[71].

Two spectrophotometric methods (first order derivative absorption \& simultaneous equation method) were described for the estimation of paracetamol and diclofenac in their tablet dosage form[72].

Hegazyet al,[73] developed potent processing methods for resolution and quantitation of paracetamol, chlorzoxazone and diclofenac based on the application of continuous wavelet transform and Savitsky-Golay derivatization as univariate spectrophotometric methods, partial least squares (PLS) and synergy interval partial least squares (siPLS) as multivariate methods.

\subsection{Chromatographic methods:}

Estimation of diclofenac sodium in serum and its use in pharmacokinetic studies was determinedusing $\mathrm{C}_{8}$ reversed-phase column, flufenamic acid as the internal standard and acetonitrile for protein precipitation[74].

High-performance liquid chromatographic (HPLC) method was developed for the quantification of diclofenac in human plasma using ibuprofen as internal standard and purification by solid-phase extraction using Abselut Nexus cartridges (Varian) [75].

HPLC method for the determination of diclofenac in synovial fluid with a one-step liquid-liquid extraction extraction procedure using isopropyl alcohol and n-hexane was constructed[76].

RP-HPLChas been developed for the simultaneous estimation of diclofenac sodium and rabeprazole sodium in pharmaceutical formulations using a HiQSiL $\mathrm{C}_{18}$ column with a mobile phase consisting of methanol:water, (80:20, $\mathrm{v} / \mathrm{v}$ ), at a flow rate of $1.25 \mathrm{~mL} / \mathrm{min}[77]$. 
Simultaneous determination of diclofenac sodium and papaverine hydrochloride in tablets was developed using a Zorbax SB $\mathrm{C}_{18}$ column, mobile phase of methanol: water $(60: 40, \mathrm{v} / \mathrm{v})$, flow rate: $1 \mathrm{~mL} / \mathrm{min}$ and $\mathrm{UV}$ detection at 278 $\mathrm{nm}[78]$.

Nasiret al,[79]developed HPLC-UV method for the simultaneous estimation of timolol, rosuvastatin, and diclofenac sodium in pharmaceuticals, human plasma and aqueous humor using Hypersil BDS $\mathrm{C}_{18}$ column and applying $0.2 \%$ triethylamine and acetonitrile $(40: 60, \mathrm{v} / \mathrm{v})$, in isocratic mode as mobile phase with a flow rate of $1 \mathrm{ml} / \mathrm{min}$.

Determination of diclofenac sodium and lidocaine hydrochloride in presence of their impurities by $\mathrm{C}_{18}$ column with gradient elution of the mobile phase composed of $0.05 \mathrm{M}$ orthophosphoric acid and acetonitrile was described[80].

Polymer monolithic column based on a green poly deep eutectic solvent was prepared for in-tube solid phase microextraction of non-steroidal anti-inflammatory drugs in aqueous samples[81].

A CN bonded phase column (RP-HPLC) was used for theestimation of paracetamol and diclofenac sodium with a mobile phase methanol-potassium dihydrogen phosphate $(0.05 \mathrm{M}),(45: 55)$ at flow rate $1 \mathrm{ml} / \mathrm{min}[82]$.

A chromatographic method for the determination of paracetamol, tizanidine, and diclofenac was carried out on a Hypersil ODS, $\mathrm{C}_{18}$ column using a mobile phase aqueous $0.2 \%$ ammonium carbonate-methanol (60:40, v/v) at a flow rate of $1 \mathrm{~mL} / \mathrm{min}[83]$.

Paracetamol, chlorzoxazone and diclofenac sodium were separated and assayed by isocratic RP-HPLC on an inertsil $\mathrm{C}_{18}$ column, mobile phase composed of a mixture of phosphate buffer $\left(0.02 \mathrm{M} \mathrm{KH}_{2} \mathrm{PO}_{4}, \mathrm{pH}\right.$ adjusted to 3.7 using orthophosphoric acid), acetonitrile and methanol in the ratio of (25: 25: 50) as a mobile phase at a flow rate of 1 $\mathrm{mL} / \min [84]$.

Jana, Kallolet al,[85]developed RP-HPLC method for determination of paracetamol and diclofenac using $\mathrm{RP}_{18}$ column and a mobile phase of acetonitrile : methanol (90:10, $\mathrm{v} / \mathrm{v}$ ) at flow rate $1 \mathrm{ml} / \mathrm{min}$.

HPLC method has been developed for determination of famotidine, paracetamol and diclofenac in their pharmaceutical formulations on $\mathrm{C}_{8}$ column with mobile phase of methanol and $0.01 \mathrm{M}$ sodium dihydrogen phosphate $(80: 20, v / v)[86]$.

Diclofenac sodium was spotted on silica gel 60 F254 precoated plates, using the mobile phase toluene : acetone : glacial acetic acid $(80: 30: 1, \mathrm{v} / \mathrm{v} / \mathrm{v})$ to be determined by densitometric analysis at $280 \mathrm{~nm}$ [87].

Diclofenac sodium and paracetamol analysis was performed on silica gel 60F254 HPTLC plates with toluene
- ethyl acetate - methanol - formic acid, (5: 4: 1: 0.01, $\mathrm{v} / \mathrm{v} / \mathrm{v} / \mathrm{v}$ ) as mobile phase[88].

TLC was used for the identification and separation of paracetamol and diclofenac sodium on silica gel $\mathrm{H}$ layers using surfactant mediated mobile phase systems[89].

Diclofenac can be converted into its methyl or ethyl ester in methanol or ethanol containing $0.1 \%$ or $0.5 \%$ sulfuric acid then determined in plasma by gas-liquid chromatography with electron capture detection[90].

Determination of diclofenac in pharmaceutical preparations by linear sweep voltammetry and gas chromatography with mass spectrometry detection was presented[91].

\subsection{Miscellaneous methods:}

Capillary zone electrophoresis was employed for the determination of diclofenac sodium using an end-column amperometric detection with a carbon fiber microelectrode[92].

Diclofenac sodium was investigated by cyclic voltammetric and differential pulse voltammetric techniques, using a tyrosine-modified carbon paste electrode[93].

Diclofenac sodium can be determined based on gold nanoparticle/multi-walled carbon nanotube modified glassy carbon electrode[94].

Estimation of trace amount of diclofenac in whole blood sample was performed by coupling of electromembrane extraction and stripping fast fourier transform continuous cyclic voltammetry[95].

Simultaneous potentiometric and fluorimetric determination of diclofenac in a sequential injection analysis system in which the potentiometric detection was carried out with an ion-selective electrode based on a cyclodextrin while for the fluorimetric determination, the sample was previously subjected to in-line irradiation with UV light[96].

Iron(II)-phthalocyanine can be used as a novel recognition sensor for selective potentiometric determination of diclofenac and warfarin drugs[97].

Diclofenac can be assayed in pharmaceutical preparations by diffuse reflectance photometry in the visible region of the spectrum[98].

Gimeneset al,[99] developed an amperometric method for determination of diclofenac in pharmaceutical formulations using flow injection method with multiple pulse amperometric detection using a boron-doped diamond electrode. 
A method for fast and simultaneous determination of diclofenac and its common counter-ions using capillary electrophoresis with capacitively coupled contactless conductivity detection was developed by Cunhaaet al[100].

An electrochemical sensor was developed for estimation of diclofenac based on functionalized multi-walled carbon nanotubes and gold-platinum bimetallic nanoparticles modified gold electrode[101].

Determination of ceftriaxone, ceftizoxime, paracetamol, and diclofenac sodium by capillary zone electrophoresis in pharmaceutical formulations and in human blood serum was estimated[102].

The electrochemical determination of paracetamol and diclofenac by using poly(diallyldimethylammonium chloride) functionalized graphene was developed by okothet al[103].

The quantification of diclofenac in presence of naproxen and paracetamol was reported using differential pulse voltammetry and an artificial neural network model using a carbon paste electrode[104].

\section{Paracetamol (Acetaminophen)}<smiles>CC(=O)Nc1ccc(O)cc1</smiles>

\section{Molecular Formula: $\mathrm{C}_{8} \mathrm{H}_{9} \mathrm{NO}_{2}$.}

Chemical name: $N$-(4-Hydroxyphenyl) acetamide.

\section{M.Wt: 151.2.}

Mode of Action and uses: Analgesic; antipyretic.

\section{Characters:}

Appearance: White or almost white, crystalline powder.

Solubility: Sparingly soluble in water, freely soluble in alcohol, very slightly soluble in methylene chloride.

Melting point: $168^{\circ} \mathrm{C}$ to $172^{\circ} \mathrm{C}$.

Storage: Protected from light.

\section{Methods of determination:}

\section{Pharmacopeial assay:}

British pharmacopeia[3]:
Dissolve $0.300 \mathrm{~g}$ in a mixture of $10 \mathrm{ml}$ of water $R$ and 30 $\mathrm{ml}$ of dilute sulphuric acid $R$. Boil under a reflux condenser for $1 \mathrm{~h}$, cool and dilute to $100.0 \mathrm{ml}$ with water $R$. To 20.0 $\mathrm{ml}$ of the solution add $40 \mathrm{ml}$ of water $R, 40 \mathrm{~g}$ of ice, $15 \mathrm{ml}$ of dilute hydrochloric acid $R$ and $0.1 \mathrm{ml}$ of ferroin $R$. Titrate with $0.1 \mathrm{M}$ cerium sulphate until a greenish-yellow colour is obtained. Carry out a blank titration.

$1 \mathrm{ml}$ of $0.1 \mathrm{M}$ cerium sulphate is equivalent to $7.56 \mathrm{mg}$ of $\mathrm{C}_{8} \mathrm{H}_{9} \mathrm{NO}_{2}$.

\section{United States pharmacopeia[4]:}

Method: Chromatographic

Mode: LC

Detector: UV $243 \mathrm{~nm}$

Column: $3.9-\mathrm{mm} \times$ x $30-\mathrm{cm}$ column $\mathrm{C}_{18}$

Flow rate: $1.5 \mathrm{~mL} / \mathrm{min}$

Injection size: $10 \mu \mathrm{L}$

\section{Other Methods of determination:}

\subsection{Spectrophotometric methods:}

A simple, specific, accurate and precise spectrophotometric method was settled for simultaneous determination of paracetamol and orphenadrine citrate in their pure form and in their pharmaceutical formulation. Spectrum subtraction technique has been used in simultaneous determination of both drugs without prior separation[105].

The chromogenic reagent, sodium nitroprusside, can react with paracetamol in a basic solution to form a product with colored 0-nitrosamines for spectrophotometric determination of paracetamol in pharmaceutical and biological samples[106].

A simple colorimetric method for determination of paracetamol to assess risk in patients with acute paracetamol poisoning was developed[107].

First derivative UV spectrophotometry, with zero-crossing measurement, first derivative of the ratio-spectra and the use of partial least squares (PLS) regression analysis as a multivariate spectrophotometric method was reported[108].

Gondaliaet al, [109] developed simultaneous equation method for estimation of ibuprofen and paracetamol in soft gelatin capsule.

Ibuprofen and paracetamol were determined by using derivatives of the ratio spectra method[110]. 
Simultaneous equation and Q-value determination were prescribed for simultaneous estimation of paracetamol and ibuprofen in pure and tablet dosage form[111].

Six simple, specific, accurate and precise spectrophotometric methods were developed for the firsttime analysis of some co-administered drugs with paracetamol in their mixture form without prior separation. Paracetamol \& orphenadrine citrate were determined by using dual wavelength, bivariate, ratio difference, ratio derivative and mean centering of ratio spectra methods. Paracetamol \& caffeine were determined by using ratio difference, ratio derivative and mean centering of ratio spectra methods. Paracetamol \& diclofenac sodium were determined by using advanced absorption subtraction, ratio difference, ratio derivative and mean centering of ratio spectra methods. All of these methods were validated according to ICH guidelineswhere accuracy, precision, repeatability and robustness were found to be within the accepted limits[112].

Paracetamol and ibuprofen were estimated by using the simultaneous equation UV spectrophotometric method in bulk and pharmaceutical dosage form[113].

The application of first-order derivative and wavelet transforms to UV spectra and ratio spectra has been described for the determination of ibuprofen and paracetamol in pharmaceutical dosage form[114].

A zero-crossing derivative spectrophotometric method for determination of ternary mixture of paracetamol, ibuprofen and caffeine in tablets was developed by Saraanet al[115].

Paracetamol and phenacetin can be reacted with sodium 1,2-naphthoquinone-4-sulphonate and cetyltrimethyl ammonium bromide in alkaline medium to be determined by UV-Vis spectrophotometry[116].

Spectrophotometric determination of paracetamolwith microwave assisted alkaline hydrolysis of paracetamol to p-aminophenol which reacts with $\mathrm{S} 2-$ in the presence of $\mathrm{Fe} 3+$ as oxidant to produce a methylene blue-like dye having an absorptivity maximum at $540 \mathrm{~nm}$ was presented[117].

Partial least squares regression (PLS), genetic algorithm coupled with PLS and principal component-artificial neural network were used for chemometric analysis for spectrophotometric estimation of paracetamol, ibuprofen and caffeine in their pharmaceuticals[118].

Paracetamol and tramadol spectrophotometric data obtained were processed and determined in tablets by means of partial least squares (PLS) and genetic algorithm coupled with PLS methods[119].

Spectrophotometric determination of paracetamol has been validated in some manufactured tablets in Iraqi markets like Panadol ${ }^{\circledR}$, Adol $^{\circledR}$, and Panda ${ }^{\circledR}$ by using different solvents[120].

\subsection{Chromatographic methods:}

Micro-assay for paracetamol in blood and plasma in which samples were prepared by precipitation with trichloroacetic assay solution and the drug quantified by reversed phase liquid chromatography with dual electrode electrochemical detection in the redox mode was described[121].

C18 column using a pure micellar mobile phase of $0.02 \mathrm{M}$ sodium dodecyl sulfate at $\mathrm{pH} 7$ with the use of electrochemical and UV detection was developed for determination of paracetamol in physiological fluids by liquid chromatography[122].

S.S. Narwade[123]developed a chromatographic technique in which stainless steel column packed with ocadesilance bonded to porous silica 10 micrometer was used at a flow rate of $0.2 \mathrm{ml} / \mathrm{min}$ at 20 micrometer loop injector at $272 \mathrm{~nm}$.

Paracetamol was separated from plasma samples by a single protein precipitation step then determined by HPLCPDA detection (a Knauer Eurospher II, C18 column) and its application to PK/PD studies with arthritic rats[124].

Simultaneous determination of paracetamol, caffeine and propyphenazone in ternary mixtures was estimated by micellar electrokinetic capillary chromatography[125].

Paracetamol and its metabolites can be separated in a synthetic mixture using slightly acidic aqueous alcoholic eluents (e.g. water - methanol -formic acid, 85:15:0.15, $\mathrm{v} / \mathrm{v} / \mathrm{v}$ ) on octadecyl silica to remove the residual hydroxyl groups[126].

A method for the determination of paracetamol and chlorpheniramine in human plasma has been developed in which the extraction of paracetamol and chlorpheniramine with diethyl ether, followed by the determination of both drugs by an LC-MS-MS method, using 2 -acetamidophenol as internal standard was carried out[127].

The quantification of paracetamol, paracetamol glucuronide and paracetamol sulphate in plasma and urine was reported using a single isocratic reversed phase highperformance liquid chromatography assay by utilizing a reversed-phase C18 column and a mobile phase composed of potassium dihydrogen orthophosphate $(0.1 \mathrm{M})-$ isopropanol-tetrahydrofuran (100:1.5:0.1, v/v/v)[128].

Simultaneous determination of paracetamol and tramadol hydrochloride in a binary mixture was developed using high- performance liquid chromatography with UV detection (HPLC-UV) and gas chromatography with mass spectrometry (GC-MS) techniques[129]. 
Paracetamol, pseudoephedrine, dextrophan and chlorpheniramine were separated in human plasma by liquid chromatography-tandem mass spectrometry using diphenhydramine as internal standard and separated on a YMC-ODS-AQ C18 Column with mobile phase consisting of $0.3 \%(\mathrm{v} / \mathrm{v})$ acetic acid and methanol at a flow rate of $0.30 \mathrm{~mL} / \mathrm{min}[130]$.

RP-HPLC using a LiChrospher ${ }^{\circledR}$ RP18 column and isocratic elution with a flow rate of $1 \mathrm{ml} / \mathrm{min}$ for determination of paracetamol and codeine phosphate where a mobile phase consists of a mixture of acetonitrile andbuffer solution $(\mathrm{pH}=2.5)(15: 85)$ was developed by Maslarskaet al[131].

HPTLC separation of paracetamol followed by densitometry measurements of spot at $270 \mathrm{~nm}$ was developed for identification of paracetamol from biological material using benzene: ethanol (90:10) as mobile phase and the use of a new chromomeric spray reagent formaldehydesulfuric acid which gives dark green colored spot with paracetamol[132].

Quantitative extraction of paracetamol from serum with derivatization and gas chromatography was reported[133].

\subsection{Miscellaneous methods:}

The electrochemical detection of paracetamol has been determined by investigating the electrochemical behaviors of paracetamol on screen printed graphene electrodes by cyclic voltammetry[134].

Square-wave voltammetric determination of paracetamol and codeine in pharmaceutical and human body fluid samples using a cathodicallypretreated boron-doped diamond electrode was reported[135].

Differential pulse voltammetric method for estimation of paracetamol by using a nanogold modified indium tin oxide electrode at $\mathrm{pH} 7.2$ was prescribed[136].

Khaskheliaet al,[137] developed a differential pulse voltammetric method for determination of paracetamol in tablet and urine samples at a micro-crystalline natural graphite-polystyrene composite film modified electrode.

Graphene oxide and hexachloroplatinic acid were electrochemically reduced on a glassy carbon electrode surface to form a graphene-platinum nanoparticles composite and then coated with nafion film in which paracetamol and domperidone can be assayed by using adsorptive stripping square wave voltammetry[138].

Poly(4-amino-3-hydroxynaphthalene sulfonic acid)-modified glassy carbon electrode was prepared for estimation of caffeine and paracetamol using square-wave voltammetry[139].
The advantages of nanotechnology and chemometrics can be combined to enhance the performance of electroanalysis of ascorbic acid, paracetamol and guaifenesin using a sequential experimentation strategy[140].

Indirect determination of paracetamol was accomplished by using a capillary electrophoresis -chemiluminescence detection system based on the inhibitory effect on a luminol-potassium hexacyanoferrate(III) reaction[141].

Chemiluminescensce method was proposed for determination of paracetamol and isoniazid in pharmaceutical preparations based on enhancing effect of isoniazid and also decreasing effect of paracetamol on the graphene oxide-luminol-dissolved oxygen chemiluminescence reaction in a strongly alkaline medium[142].

The determination of paracetamol in the presence of uric acid in body fluid based on the reduction of N-acetyl-pbenzoquinoneimine formed on the electrochemically treated pencil graphite electrode was prescribed[143].

An electrochemical method using a glassy carbon electrode modified with graphene oxide and nickel oxide nanoparticles was prescribed for the estimation of paracetamol and ciprofloxacin[144].

Electrochemical sensor based on palladium-reduced graphene oxide modified with gold nanoparticles for simultaneous determination of paracetamol and 4-Aminophenol was developed by Wang, Huijuanet al,[145].

Electrocatalysis of $\mathrm{Cu}-\mathrm{MOF} /$ graphene composite and its Sensing application for electrochemical assay of dopamine and paracetamol was prescribed[146].

Simultaneous determination of ascorbic acid, caffeine and paracetamol in drug formulations by differentialpulse voltammetry using a glassy carbon electrode in which perchloric acid $(0.1 \mathrm{M})$ - methanol $(1+1)$ was used both as a solvent and supporting electrolyte was developed[147].

A method in which carbon-ceramic electrode modified with a thin film of single-walled carbon nanotubes was developed for the simultaneous determination of paracetamol and caffeine[148].

\section{References}

[1] J.F. Committee, British National Formulary (BNF) 76, London: Pharmaceutical Press. (2018) 1616.

[2] S.C. Sweetman, Martindale : the complete drug reference, London, Chicago, Pharmaceutical Press. (2009) 3694.

[3] British pharmacopoeia, London: Medicines and Healthcare Products Regulatory Agency. 1,2 (2017). 
[4] The United States pharmacopeia. National formulary, Rockville (MD): United States Pharmacopeial Convention. 1,2 (2018).

[5] Yanhong Lei, Spectrophotometric Method for the Assay of Aspirin, Applied Mechanics and Materials. 605 (2014) 2097-2100. doi:10.4028/www.scientific.net/ AMM.602-605.2097.

[6] I.A. Muni, J.L. Leeling, R.J. Helms, N. Johnson, J.J. Bare, B.M. Phillips, Improved Colorimetric Determination of Aspirin and Salicylic Acid Concentrations in Human Plasma, Journal of Pharmaceutical Sciences. 67 (1978) 289-291.

[7] K. Kitamura, M. Takagi, K. Hozumi, Determination of Aspirin and Salicylic Acid in Aspirin Tablets by Second Derivative Spectrometry, Chem. Pharm. Bull. 32 (1984) 1484-1490.

[8] B. w. Glombit, P. c. Schmidt, Comparison of Three New Spectrophotometric Methods for Simultaneous Determination of Aspirin and Salicyclic Acid in Tablets without Separation of Pharmaceutical Excipients, Journal of Pharmaceutical Sciences. 83 (1994) 751-757.

[9] M.S. El-Din, M. Eid, A.M. Zeid, Simultaneous Determination of Methocarbamol and Aspirin Binary Mixture in their Combined Tablets by Derivative and Ratio Derivative Spectrophotometry, Analytical Methods. 7 (2014) 5674-5681.

[10] A.M. Saeed, N.Q. Ahmed, Estimation of Paracetamol, Aspirin, Ibuprofen, Codeine and Caffeine in some formulated commercial dosage using UV-Spectroscopic method, European Journal Of Pharmaceutical and Medical Research. 4 (2017) 33-38.

[11] P. A.G.Fogg, P.J. Sausins, J.R. Smithson, The Determination of Paracetamol and Aspirin in Mixtures by Non-aqueous Potentiometric Titrimetry or by Ultraviolet Spectrophotometry, Analytica Chimica Acta. 49 (1970) 342-345.

[12] K.T. Koshy, Chromatographic Method for the Simultaneous Determination of Aspirin, Caffeine, and Acetaminophen, Journal of Pharmaceutical Sciences. 53 (1964) 1280-1282.

[13] B. Applications, E.S.P.B. V, D.C. Mays, D.E. Sharp, C.A. Beach, R.A. Kershaw, J.R. Bianchine, N. Gerber, T.O. State, T. Avenue, Improved method for the Determination of Aspirin and its metabolites in Biological Fluids by High-Performance Liquid Chromatography: Applications to Human and Animal Studies, Journal of Chromatography. 311 (1984) 301-309.

[14] P. Taylor, C.J. Fu, S. Melethil, W.D. Mason, Method for Determination of Aspirin and Salicylic Acid in Rat Whole Blood by High Pressure Liquid Chromatography,
Analytical Letters. 18 (2006) 37-41.

[15] G.P. Mcmahon, M.T. Kelly, Determination of Aspirin and Salicylic Acid in Human Plasma by ColumnSwitching Liquid Chromatography Using On-Line SolidPhase Extraction, Analytical Chemistry an Indian Journal. 70 (1998) 409-414.

[16] M. Gandhimathi, T.K. Ravi, A. Abraham, R. Thomas, Simultaneous Determination of Aspirin and Isosorbide 5-mononitrate in Formulation by Reversed Phase High Pressure Liquid Chromatography, Journal of Pharmaceutical and Biomedical Analysis. 32 (2003) 1145-1148.

[17] E. Yamamoto, S. Takakuwa, T. Kato, N. Asakawa, Sensitive Determination of Aspirin and its metabolites in Plasma by LC-UV using On-line Solid-Phase Extraction with Methylcellulose-Immobilized anion-Exchange Restricted Access Media, Journal of Chromatography B: Analytical Technologies in the Biomedical and Life Sciences. 846 (2007) 132-138.

[18] S.K. Malisetty, C. Rambabu, Simultaneous Determination of Aspirin and Esomeprazole Magnesium in Combined Tablets by Validated UPLC Method, Pharmaceutical Methods. 4 (2013) 26-29.

[19] P.K. Sinha, M.C. Damle, K.G. Bothara, A Validated Stability Indicating HPTLC Method for Determination of Aspirin and Clopidogrel Bisulphate in Combined Dosage Form, Eurasian Journal of Analytical Chemistry. 2 (2009) 152-160.

[20] R. May, U. Sim, Determination of Aspirin and Its Major Metabolites in Human Urine by Gas Chromatography - Mass Spectrometry, II, Michrochemical Journal. 307 (1997) 296-307.

[21] X. Wei, Z. Zhou, T. Hao, Y. Xu, H. Li, K. Lu, J. Dai, X. Zheng, L. Gao, J. Wang, Y. Yan, Y. Zhu, Specific Recognition and Fluorescent Determination of Aspirin by Using Core-Shell CdTe Quantum Dot-Imprinted Polymers, Mikrochimica Acta. 182 (2016) 1527-1534.

[22] R.N. Goyal, S. Bishnoi, B. Agrawal, Electrochemical Sensor for the Simultaneous Determination of Caffeine and Aspirin in Human Urine Samples, Journal of Electroanalytical Chemistry. 655 (2011) 97-102. doi:10.1016/j. jelechem.2011.03.008.

[23] H. Ghadimi, R.M.A. Tehrani, W.J. Basirun, N.J. Ab Aziz, N. Mohamed, S. Ab Ghani, Electrochemical Determination of Aspirin and Caffeine at Mwcnts-poly-4-vinylpyridine Composite Modified Electrode, Journal of the Taiwan Institute of Chemical Engineers. (2016) 1-9.

[24] N.F. Atta, A. Galal, E.H. El-Ads, A.E. Galal, New Insight in Fabrication of a Sensitive Nano-magnetite/ glutamine/carbon Based Electrochemical Sensor for Determination of Aspirin and Omeprazole, Journal of The 
Electrochemical Society. 166 (2019) 161-172.

[25] A.D. Vidal, P.O. Barrales, A.M. Díaz, Simultaneous Determination of Paracetamol, Caffeine and Propyphenazone in Pharmaceuticals by Means of a Single Flowthrough Uv Multiparameter Sensor, Mikrochimica Acta. 141 (2003) 157-163. doi:10.1007/s00604-002-0938-0.

[26] S. Antakli, L. Nejem, M. Dawoud, Spectrophotometric Determination of Paracetamol and Caffeine, Asian Journal of Chemistry. 26 (2014) 7016-7020.

[27] H. Tavallali, M. Sheikhaei, Simultaneous Kinetic Determination of Paracetamol and Caffeine Using $\mathrm{Cu}(\mathrm{Ii})$ neocuproine in Presence of Dodecyl Sulfate by H-point Standard Addition Method, Indian Journal of Chemistry Section A Inorganic, Physical, Theoretical and Analytical Chemistry. 48 (2009) 812-816.

[28] M.M. Sebaiy, A.A. Mattar, H-Point Assay Method for Simultaneous Determination of Paracetamol and Caffeine in Panadol Extra Dosage Forms, Canadian Journal of Biomedical Research and Techology. 3(1) (2020) 1-6.

[29] V. Vichare, P. Mujgond, V. Tambe, S.N. Dhole, Simultaneous Spectrophotometric Determination of Paracetamol and Caffeine in Tablet Formulation, International Journal of PharmTech Research. 2 (2010) 2512-2516.

[30] P. Ortega-Barrales, R. Padilla-Weigand, A. MolinaDiaz, Simultaneous Determination of Paracetamol and Caffeine by Flow Injection-Solid Phase Spectrometry Using C18 Silica Gel as a Sensing Support., Analytical Sciences. 18 (2005) 1241-1246. doi:10.2116/analsci.18.1241.

[31] A.C. Moț, F. Soponar, A. Medvedovici, C. Sârbu, Simultaneous Spectrophotometric Determination of Aspirin, Paracetamol, Caffeine, and Chlorphenamine from Pharmaceutical Formulations Using Multivariate Regression Methods, Analytical Letters. 43 (2010) 804-813. doi:10.1080/00032710903486260.

[32] A. Hakan Aktaş, F. Kitiş, Spectrophotometric Simultaneous Determination of Caffeine and Paracetamol in Commercial Pharmaceutical by Principal Component Regression, Partial Least Squares and Artificial Neural Networks Chemometric Methods, Croatica Chemica Acta. 87 (2014) 69-74. doi:10.5562/cca2214.

[33] G. Navarra, M. Moschetti, V. Guarrasi, M.R. Mangione, V. Militello, M. Leone, Simultaneous Determination of Caffeine and Chlorogenic Acids in Green Coffee by UV/ Vis Spectroscopy, Journal of Chemistry. 2017 (2017) 8.

[34] G. Alpdogan, K. Karabina, S. Sungur, Derivative Spectrophotometric Determination of Caffeine in Some Beverages, Turk J Chem. 26 (2002) 295-302.

[35] H.N. Wanyika, E.G. Gatebe, L.M. Gitu, E.K. Ngumba, C.W. Maritim, Determination of Caffeine Content of
Tea and Instant Coffee Brands Found in The Kenyan Market, African Journal of Food Science. 4 (2010) 353-358.

[36] S.S. Bharate, S.B. Bharate, Spectrophotometric and Chromatographic determination of Acetylsalicylic acid and Caffeine in pure and in tablet dosage form, Journal of Advanced Scientific Research. 3 (2012) 73-81.

[37] M.L. Altun, HPLC Method for the Analysis of Paracetamol, Caffeine and Dipyrone, Turk J Chem. 26 (2002) 521-528. doi:10.1177/0002716212461748.

[38] S. Sharma, M.C. Sharma, R. Sharma, A.D. Sharma, High Performance Liquid Chromatographic Assay method for the determination of Paracetamol and Caffeine in Tablet Formulation-in vitro dissolution studies., Journal of Pharmacy Research. 4 (2011) 1559-1561. http://search. ebscohost.com/login.aspx?direct=true $\& \mathrm{db}=\mathrm{a} 9 \mathrm{~h} \& \mathrm{AN}=74$ $388004 \&$ site $=$ ehost-live.

[39] A.P. Dewani, V.D. Chipade, R.L. Bakal, A.V. Chandewar, S.K. Kanungo, B.B. Barik, Rp-hplc-dad Method for the Determination of Phenylepherine, Paracetamol, Caffeine and Chlorpheniramine in Bulk and Marketed Formulation, Arabian Journal of Chemistry. 7 (2012) 811-816. doi:10.1016/j.arabjc.2012.07.010.

[40] V.K. Redasani, A.P. Gorle, S.J. Surana, P.S. Jain, R.A. Badhan, Simultaneous determination of chlorpheniramine maleate, phenylephrine hydrochloride, paracetamol and caffeine in pharmaceutical preparation by RP-HPLC, Chemical Industry and Chemical Engineering Quarterly. 19 (2012) 57-65. doi:10.2298/ciceq120302042r.

[41] M. Radi, Y. Ramli, M. El Karbane, S. Marzak, K. Bougrin, K. El Bourkadi, F. Ouazzani Chahdi, S. Issmaili, K. Bakhous, A. Ben Ali, Validation of a method for simultaneous determination of acetaminophen and caffeine by HPLC in different pharmaceutical forms: Tablet, capsule and sachet, Journal of Materials and Environmental Science. 7 (2016) 4608-4613.

[42] R.A.A. Muñoz, R.R. Cunha, L.M.F.C. Torres, W.T.P. Dos Santos, S.C. Chaves, M.M.A.C. Ribeiro, E.M. Richter, Simultaneous determination of caffeine, paracetamol, and ibuprofen in pharmaceutical formulations by high-performance liquid chromatography with UV detection and by capillary electrophoresis with conductivity detection, Journal of Separation Science. 38 (2015) 1657-1662. doi:10.1002/jssc.201401387.

[43] K. Delvadiya, P. Kabra, R. Kimbahune, N. Patel, L.V.G. Nargund, High-performance liquid chromatographic determination of paracetamol, propyphenazone, and caffeine in pharmaceutical formulations, Indian Journal of Pharmaceutical Education and Research. 47 (2013) 65-72. doi:10.5530/ijper.47.4.9.

[44] V.L. Narayanan, A. Austin, Determination of 
Acetaminophen and Caffeine using reverse phase liquid ( RP-LC ) chromatographic technique, Journal of Research in Pharmaceutical Sciences. 3 (2016) 5-10.

[45] R.E. Leacock, J.J. Stankus, J.M. Davis, Simultaneous Determination of Caffeine and Vitamin B6 in Energy Drinks by High-Performance Liquid Chromatography (HPLC), Journal of Chemical Education. 88 (2011) 232234.

[46] Y. Liu, X. Li, C. Yang, S. Tai, X. Zhang, G. Liu, UPLCMS-MS Method for Simultaneous Determination of Caffeine, Tolbutamide, Metoprolol, and Dapsone in Rat Plasma and its Application to Cytochrome P450 Activity Study in Rats, Journal of Chromatographic Science. 51 (2013) 26-32.

[47] J.I. Routh, W.D. Paul, N.A. Shane, E.G. Arredondo, Determination of Caffeine in Serum and Urine, Clinical Chemistry. 15 (1969) 661-668.

[48] A. Mumin, K.F. Akhter, Z. Abedin, Z. Hossain, Determination and Characterization of Caffeine in Tea, Coffee and Soft Drinks by Solid Phase Extraction and High Performance Liquid Chromatography (SPE-HPLC), Malaysian Journal of Chemistry. 8 (2006) 45-51.

[49] D. Komes, D. Horžić, A. Belščak, K.K. Ganič, A. Baljak, Determination of Caffeine Content in Tea and Maté Tea by using Different Methods, Czech J. Food Sci. 27 (2009) 213-216.

[50] M.G. Karau, J.N. Kihunyu, N.M. Kathenya, L.N. Wangai, D. Kariuki, R.H. Kibet, Determination of Caffeine content in non-Alcoholic Beverages and energy Drinks using HPLC-UV Method, African Journal of Drug \& Alcohol Studies. 9 (2010) 21.

[51] S. Youse, M. Kamankesh, S. Jazaeri, Analytical Methods Method Used for the Determination of Caffeine in Tea and Energy Drink Samples , and Method Optimization using a Central Composite Design, Analytical Methods. 9 (2017) 1665-1671. doi:10.1039/c6ay03490j.

[52] M. Shiferaw, I. Alemayehu, Determination of Caffeine Content of Bale Coffee Using HPLC Analysis, Food Science and Quality Management. 73 (2018) 23-32.

[53] K. Darwish, I. Salama, S. Mostafa, M. El-sadek, Validated Stability-Indicating Reversed-Phase-HPLC Method for Simultaneous Determination of Orphenadrine Citrate, Caffeine and Aspirin, Chem. Pharm. Bull. 60 (2012) 14261436.

[54] S.P.P. N, S. Gaude, A. Palekar, RP-HPLC Method Development and Validation for Simultaneous Estimation of Aspirin , Caffeine and Orphenadrine citrate in Tablet Formulation, International Journal of Science and Research (IJSR). 5 (2016) 2014-2017.
[55] C. Oellig, J. Schunck, W. Schwack, Determination of caffeine, theobromine and theophylline in Mate beer and Mate soft drinks by high-performance thin-layer chromatography, Journal of Chromatography A. 1533 (2018) 208-212.

[56] S. Venkatesh, M.M. Swamy, Y.S.R. Reddy, B. Suresh, M. Sethuraman, A Simple method for determination of Caffeine content in Tea samples, Ancient Science of Life. 14 (1994) 35-38.

[57] M. Gamal, N.W. Ali, M.R. Elghobashy, M. Abdelkawy, Simultaneous Determination of Ternary Mixture of Aspirin , Caffeine and Orphenadrine Citrate by Simple RP-TLC Spectrodensitometric Method, British Journal of Pharmaceutical Research. 14 (2017) 1-11. doi:10.9734/ BJPR/2016/31194.

[58] A. Yiğit, Y. Yardim, Z. Şentürk, Voltammetric Sensor Based on Boron-Doped Diamond Electrode for Simultaneous Determination of Paracetamol, Caffeine, and Aspirin in Pharmaceutical Formulations, IEEE Sensors Journal. 16 (2016) 1674-1680. doi:10.1109/ JSEN.2015.2503436.

[59] J.-Y. Sun, K.-J. Huang, S.-Y. Wei, Z.-W. Wu, F.-P. Ren, A Graphene-based Electrochemical Sensor for Sensitive Determination of Caffeine, Colloids and Surfaces B: Biointerfaces. 84 (2011) 421-426.

[60] C.S. Bizzotto, A.D. MeinHart, C.A. Ballus, G. Ghiselli, H.T. Godoy, Comparison of Capillary Electrophoresis and High Performance Liquid Chromatography Methods for Caffeine Determination in Decaffeinated Coffee, Food Science and Technology. 33 (2013) 186-191.

[61] J.C. Botello, G. Pérez-Caballero, Spectrophotometric determination of Diclofenac Sodium with Methylene blue, Talanta. 42 (1995) 105-108.

[62] Y.K. Agrawal, K. Shivramchandra, Spectrophotometric determination of Diclofenac Sodium in Tablets, Journal of Pharmaceutical and Biomedical Analysis. 9 (1991) 97-100.

[63] M.S. Garcia, M.I. Albero, C. Sanchez-Pedreno, J. Molina, Flow-injection Spectrophotometric Determination of Diclofenac Sodium in Pharmaceuticals and Urine Samples, Journal of Pharmaceutical and Biomedical Analysis. 17 (1998) 267-273.

[64] M.S. Garcia, C. Sanchez-Pedreno, M.I. Albero, C. Garcia, Flow-Injection Spectrophotometric Determination of Diclofenac or Mefenamic Acid in Pharmaceuticals, Mikrochimica Acta. 136 (2001) 67-71.

[65] A.M. El-Didamony, A.S. Amin, Adaptation of a Color Reaction for Spectrophotometric Determination of Diclofenac Sodium and Piroxicam in Pure Form and in Pharmaceutical Formulations, Analytical Letters. 37 
(2004) 1151-1162.

[66] A.A. Matin, M.A. Farajzadeh, A. Jouyban, A Simple Spectrophotometric Method for Determination of Sodium Diclofenac in Pharmaceutical Formulations, Farmaco. 60 (2005) 855-858.

[67] J. Ghasemi, A. Niazi, S. Ghobadi, Simultaneous Spectrophotometric Determination of Benzyl Alcohol and Diclofenac in Pharmaceutical Formulations by Chemometrics Method, Journal of the Chinese Chemical Society. 52 (2005) 1049-1054.

[68] M.M. Sebaiy, A.A. Mattar, H-Point Assay Method for Simultaneous Determination of Paracetamol and Diclofenac Sodium in Their Combined Pharmaceutical Dosage Forms, Open Journal of Biotechnology \& Bioengineering Research. 4(1) (2020) 001-005.

[69] A.R. Khaskheli, Sirajuddin, K. Abro, S.T.H. Sherazi, H.I. Afridi, S.A. Mahesar, M. Saeed, Simpler and Faster Spectrophotometric Determination of Diclofenac Sodium in Tablets, Serum and Urine Samples, Pak. J. Anal. Environ. Chem. 10 (2009) 53-58.

[70] Q.N. Rashid, M.H. Bakir, S.O. Baban, Spectrophotometric determination of Diclofenac Sodium in pure form and in the pharmaceutical preparations, Tikrit Journal of Pure Science. 21 (2016) 76-80.

[71] R. Sharma, G. Pathodiya, G.P. Mishra, J. Sainy, Spectrophotometric Methods for Simultaneous Estimation of Paracetamol and Diclofenac Sodium in Combined Dosage Form by Application of Hydrotropic Solubilization, Journal of Pharmaceutical Sciences and Research. 2 (2010) 821-826.

[72] D. Phaneemdra, G. Nagamalleswari, Quantitative Analysis of Paracetamol and Diclofenac in Combined Dosage form by First derivative and Simultaneous Equation method in Application to the determination of Dissolution study, International Journal of Pharmaceutical Sciences and Research. 3 (2012) 3871-3876.

[73] M.A. Hegazy, M.S. Elshahed, S.S. Toubar, M.I. Helmy, Efficient processing of Single and Multiple Spectral Variables for Resolution and Quantitation of Paracetamol , Chlorzoxazone and Diclofenac, Journal of Advanced Pharmacy Research. 0547 (2018) 269-282.

[74] Y.M. El-Sayed, M.E. Abd El-Hameed, M.S. Suleiman, N. Najib, A Rapid and Sensitive High-performance Liquid Chromatographic Method for The Determination of Diclofenac Sodium in Serum and its Use in Pharmacokinetic Studies, J. Pharm. Pharmacol. 40 (1988) 727-729.

[75] C. Arcelloni, R. Lanzi, S. Pedercini, G. Molteni, I. Fermo, A. Pontiroli, R. Paroni, High-performance Liquid Chromatographic Determination of Diclofenac in Human Plasma after Solid-phase Extraction, Journal of Chroma- tography B. 763 (2001) 195-200.

[76] R. Roskar, V. Kmetec, Liquid Chromatographic determination of Diclofenac in Human Synovial Fluid, Journal of Chromatography B. 788 (2003) 57-64.

[77] V. Asfak, D. Mrinalini, B. Leena, G. Rahul, Simultaneous Determination of Diclofenac Sodium and Rabeprazole Sodium in Bulk and Pharmaceutical Dosage Form by LC, Chromatographia. 66 (2007) 941-943.

[78] R. Kasperek, Determination of Diclofenac Sodium and Papaverine Hydrochloride in tablets by HPLC method, Acta Poloniae Pharmaceutica -Drug Research. 65 (2008) 403-408.

[79] F. Nasir, Z. Iqbal, A. Khan, L. Ahmada, Y. Shaha, A.Z. Khana, J.A. Khana, S. Khanb, Simultaneous Determination of Timolol Maleate, Rosuvastatin Calcium and Diclofenac Sodium in Pharmaceuticals and Physiological Fluids Using Hplc-UV, Journal of Chromatography B. 879 (2011) 3434- 3443.

[80] T.S. Belal, M.M. Bedair, A.A. Gazy, K.M. Guirguis, Validated Selective HPLC-DAD Method for the Simultaneous Determination of Diclofenac Sodium and Lidocaine Hydrochloride in Presence of Four of Their Related Substances and Potential Impurities, Acta Chromatographica. 27 (2015) 478-493.

[81] R. Wang, W. Li, Z. Chen, Solid Phase Microextraction with Poly(Deep Eutectic Solvent) Monolithic Column Online Coupled to Hplc for Determination of Non- Steroidal Anti-inflammatory Drugs, Analytica Chimica Acta Journal. 1018 (2018) 111-118.

[82] V.G. Nayak, V.R. Bhate, S.M. Purandare, P.M. Dikshit, S.N. Dhumal, C.D. Gaitonde, Rapid Liquid Chromatographic determination of Paracetamol and Diclofenac Sodium from a combined pharmaceutical dosage, Drug Development and Industrial Pharmacy. 18 (1992) 369374.

[83] F.A. Siddiqui, M.S. Arayne, N. Sultana, F. Qureshi, Development and Validation of Stability-indicating HPLC Method for The Simultaneous Determination Of Paracetamol, Tizanidine, and Diclofenac in Pharmaceuticals and Human Serum, Journal of AOAC International. 94 (2011) 150-158.

[84] M.A. Badgujar, S.G. Pingale, K. V. Mangaonkar, Simultaneous Determination of Paracetamol , Chlorzoxazone and Diclofenac Sodium in Tablet Dosage Form by High Performance Liquid Chromatography, E-Journal of Chemistry. 8 (2011) 1206-1211.

[85] K. Jana, L. Adhikari, S.. Moitra, A. Behera, Analysis of multicomponent drug formulations ( Diclofenac and Paracetamol ), Asian Journal of Pharmaceutical and Clinical Research. 4 (2011) 2-4. 
[86] M.I. Walash, F. Ibrahim, S. Abo, E. Abass, Development and Validation of HPLC Method for Simultaneous Estimation of Famotidine, Paracetamol and Diclofenac in their Raw Materials and Pharmaceutical Formulation, Analytical Chemistry Letters. 7 (2017) 421-437. doi:10.1 $080 / 22297928.2017 .1353921$.

[87] L.G. Lala, P.M. D’Mello, S.R. Naik, HPTLC determination of Diclofenac Sodium from serum, Journal of Pharmaceutical and Biomedical Analysis. 29 (2002) 539-544.

[88] V. V Dighe, R.T. Sane, S.N. Menon, H.N. Tambe, S. Pillai, V.N. Gokarn, Simultaneous Determination of Diclofenac Sodium and Paracetamol in a Pharmaceutical Preparation and in Bulk Drug Powder by High-Performance Thin-Layer Chromatography, Journal of Planar Chromatography. 19 (2006) 443-448. doi:10.1556/ JPC.19.2006.6.7.

[89] A.L.I. Mohammad, S. Sharma, Separation of Coexisting Paracetamol and Diclofenac Sodium on Silica Gel " $\mathrm{H}$ " Layers using surfactant mediated mobile phases : Identification of Diclofenac Sodium from human urine, Farmacia. 57 (2009) 201-211.

[90] M. Ikeda, M. Kawase, M. Hiramatsu, K. Hirota, S. Ohmori, Improved Gas Chromatographic Method of determining Diclofenac in Plasma, Journal of Chromatography. 183 (1980) 41-47.

[91] B. Yilmaz, U. Ciltas, Determination of Diclofenac in Pharmaceutical Preparations by Voltammetry and Gas Chromatography Methods, Journal of Pharmaceutical Analysis. 5 (2015) 153-173.

[92] W. Jin, J. Zhang, Determination of Diclofenac Sodium by Capillary Zone Electrophoresis with Electrochemical Detection, Journal of Chromatography A. 868 (2000) 101-107.

[93] B.K. Chethana, S. Basavanna, Y.A. Naik, Voltammetric Determination of Diclofenac Sodium Using Tyrosine- Modified Carbon Paste Electrode, Ind. Eng. Chem. Res. 51 (2012) 10287-10295.

[94] A. Afkhami, A. Bahiraei, T. Madrakian, Gold Nanoparticle/multi-walled Carbon Nanotube Modified Glassy Carbon Electrode as a Sensitive Voltammetric Sensor for The Determination of Diclofenac Sodium, Materials Science and Engineering C. 59 (2016) 168-176.

[95] Z. Mofidi, P. Norouzi, S. Seidi, M.R. Ganjali, Determination of Diclofenac Using Electromembrane Extraction Coupled with Stripping FFT Continuous Cyclic Voltammetry, Analytica Chimica Acta. 972 (2017) 1-8.

[96] A.M. Pimenta, A.N. Araújo, M.C.B.S.M. Montenegro, Simultaneous Potentiometric and Fluorimetric Determination of Diclofenac in a Sequential Injection Analysis System, Analytica Chimica Acta. 470 (2002) 185-194.
[97] S.S.M. Hassan, W.H. Mahmoud, M.A.F. Elmosallamy, M.H. Almarzooqi, Iron(Ii)-phthalocyanine as a Novel Recognition Sensor for Selective Potentiometric Determination of Diclofenac and Warfarin Drugs, Journal of Pharmaceutical and Biomedical Analysis. 39 (2005) 315-321.

[98] M. Tubino, R.L. de Souza, Determination of Diclofenac in Pharmaceutical Preparations by Diffuse Reflectance Photometry, Talanta. 68 (2006) 776-780.

[99] D.T. Gimenes, J.M. de Freitas, R.A.A. Munoz, E.M. Richter, Flow-Injection Amperometric Method for Determination of Diclofenac in Pharmaceutical Formulations Using a Boron-Doped Diamond Electrode, Electroanalysis. 23 (2011) $2521-2525$.

[100] R.R. Cunhaa, D.T. Gimenesa, R.A. Abarza, Munoza, C.L. do Lagob, E.M. Richter, Simultaneous Determination of Diclofenac and its Common Counter-ions in less than 1 Minute Using Capillary Electrophoresis with Contactless Conductivity Detection, Electrophoresis. 34 (2013) 1423-1428.

[101] M.M. Altai, G.H. Rounaghi, B. Deiminiat, Fabrication of A New Electrochemical Sensor Based on Au-pt Bimetallic Nanoparticles Decorated Multi-walled Carbon Nanotubes for Determination of Diclofenac, Microchemical Journal. 144 (2019) 254-260.

[102] A. Solangi, S. Memon, A. Mallah, N. Memon, Determination of Ceftriaxone, Ceftizoxime, Paracetamol , and Diclofenac Sodium by Capillary Zone Electrophoresis in Pharmaceutical Formulations and in Human Blood, Turk J Chem. 34 (2010) 921-933. doi:10.3906/kim-1005-628.

[103] O.K. Okoth, K. Yan, L. Liu, J. Zhang, Simultaneous Electrochemical Determination of Paracetamol and Diclofenac Based on Poly ( diallyldimethylammonium chloride ) Functionalized Graphene, Electroanalysis. 28 (2016) 76-82. doi:10.1002/elan.201500360.

[104] E.C.S. Transactions, T.E. Society, Voltammetric Determination of Diclofenac in the Presence of Paracetamol and Naproxen by an Artificial Neural Network Model Using a Carbon Paste Electrode G. Y. Aguilar-Lira, ECS Transactions. 84 (2018) 195-205.

[105] M.M. Sebaiy, A.A. Mattar, Spectrum Subtraction Method for Simultaneous Determination of Paracetamol and Orphenadrine Citrate in Their Combined Pharmaceutical Dosage Forms, Global Scientific Journals. 7(12) (2019) 1462-1468.

[106] Y. Zhan, Y. Zhang, Q. Li, X. Du, Selective Spectrophotometric Determination of Paracetamol with Sodium Nitroprusside in Pharmaceutical and Biological Samples, Journal of Analytical Chemistry. 66 (2011) 215-220. doi:10.1134/S1061934811020171.

[107] S.M.D.K.G. Senarathna, S.S. Ranganathan, N. 
Buckley, S.S.S.B.D.P. Soysa, A Quick Inexpensive Laboratory Method in Acute Paracetamol Poisoning Could Improve Risk Assessment , Management and Resource Utilization, Indian Journal of Pharmacology. 44 (2012) 463-468. doi:10.4103/0253-7613.99305.

[108] W.S. Hassan, Determination of Ibuprofen and Paracetamol in Binary Mixture Using Chemometric-Assisted Spectrophotometric Methods, American Journal of Applied Sciences. 5 (2008) 1005-1012.

[109] R. Gondalia, R. Mashru, P. Savaliya, Development and Validation of Spectrophotometric Methods for Simultaneous Estimation of IBUPROFEN and PARACETAMOL in Soft gelatin capsule by Simultaneous Equation Method, International Journal of ChemTech Research. 2 (2010) 1881-1885.

[110] Y.M. Issa, S.I.M. Zayed, I.H.I. Habib, Simultaneous Determination of Ibuprofen and Paracetamol Using Derivatives of the Ratio Spectra Method, Arabian Journal of Chemistry. 4 (2011) 259-263. doi:10.1016/j.arabjc.2010.06.044.

[111] R.S. Joshi, N.S. Pawar, S.S. Katiyar, D.B. Zope, A.T. Shinde, Development And Validation of UV Spectrophotometric Methods for Simultaneous Estimation of Paracetamol and Ibuprofen in Pure and Tablet Dosage Form, Der Pharmacia Sinica. 2 (2011) 164-171.

[112] M.M. Sebaiy, S.M. El-adl, A.A. Mattar, Different techniques for overlapped UV spectra resolution of some co-administered drugs with paracetamol in their combined pharmaceutical dosage forms, Spectrochimica Acta Part A: Molecular and Biomolecular Spectroscopy. 224 (2020) 117429. doi:10.1016/j.saa.2019.117429.

[113] S. Harshini, G. Priyanka, K. Swathi, V.R. Kumari, M.A. Haque, V.V.L.N. Prasad, Simultaneous Estimation of Paracetamol and Ibuprofen in Bulk and Pharmaceutical Dosage Form by Using UV- Spectrophotomrtic Method, International Journal of Innovative Pharmaceutical Sciences and Research. 2 (2014) 1854-1860.

[114] V.D. Hoang, D. Thi, H. Ly, N.H. Tho, H. Minh, T. Nguyen, UV Spectrophotometric Simultaneous Determination of Paracetamol and Ibuprofen in Combined Tablets by Derivative and Wavelet Transforms, The Scientific World Journal. 2014 (2014) 13.

[115] S.M.D. Saraan, S.M. Sinaga, Muchlisyam, Development Method for Determination of Ternary Mixture of Paracetamol, Ibuprofen and Caffeine in Tablet Dosage Form Using Zero-crossing Derivative Spectrophotometric, International Journal of PharmTech Research. 7 (2015) 349-353.

[116] P. Nagaraja, K.C.S. Murthy, K.S. Rangappa, Spectrophotometric Method for the Determination of Paracetamol and Phenacetin, Journal of Pharmaceutical and
Biomedical Analysis. 17 (1998) 501-506.

[117] C. Xu, B. Li, Spectrophotometric Determination of Paracetamol with Microwave Assisted Alkaline Hydrolysis, Spectrochimica Acta Part A: Molecular and Biomolecular Spectroscopy. 60 (2004) 1861-1864.

[118] M.R. Khoshayand, H. Abdollahi, M. Shariatpanahi, A. Saadatfard, A. Mohammadia, Simultaneous Spectrophotometric Determination of Paracetamol, Ibuprofen and Caffeine in Pharmaceuticals by Chemometric Methods, Spectrochimica Acta Part A: Molecular and Biomolecular Spectroscopy. 70 (2008) 491-499.

[119] S. Glavanovic, M. Glavanovic, V. Tomisié, Simultaneous quantitative determination of paracetamol and tramadol in tablet formulation using UV spectrophotometry and chemometric methods, Spectrochimica Acta Part A: Molecular and Biomolecular Spectroscopy. 157 (2016) 258-264.

[120] A.M. Saeed, Spectrophotometric Determination of Paracetamol in Some Manufactured Tablets in Iraqi markets, International Journal of Pharmaceutical Sciences Review and Research. 42 (2017) 53-57.

[121] R. Whelpton, K. Fernandes, K.A. Wilkinson, D.R. Goldhill, Determination of Paracetamol (Acetaminophen) in Blood and Plasma Using High Performance Liquid Chromatography with Dual Electrode Coulometric Quantification in the Redox Mode, Biomedical Chromatography. 7 (1993) 90-93.

[122] D. Bose, A. Durgbanshi, Rapid Determination of Acetaminophen in Physiological Fluids by Liquid Chromatography Using SDS Mobile Phase and ED Detection, Journal of Chromatographic Science. 43 (2005) 313-318.

[123] S.S. Narwade, Qualitative and Quantitative Analysis of Paracetamol in Different Drug Samples by HPLC Technique, IOSR Journal of Applied Chemistry. 7 (2014) 46-49.

[124] A.M. Domínguez-ramírez, F.J. López-muñoz, J. Raúl, G. Alarcón, A. Desiree, L.A. Moreno-rocha, HPLC-PDA Method for the Quantification of Paracetamol in Plasma : Application to PK / PD Studies with Arthritic Rats, International Journal of Pharmacy and Pharmaceutical Sciences. 9 (2017) 233-239.

[125] D. Emre, N. Özaltin, Simultaneous Determination of Paracetamol, Caffeine and Propyphenazone in Ternary Mixtures by Micellar Electrokinetic Capillary Chromatography, Journal of Chromatography B: Analytical Technologies in the Biomedical and Life Sciences. 847 (2007) 126-132. doi:10.1016/j.jchromb.2006.09.036.

[126] J.H. Knox, J. Jurand, Determination of Paracetamol and its Metabolites in Urine by High-Performance Liquid Chromatography using Reversed-Phase Bonded 
Supports, JournaI of Chromatography. 142 (1977) 651670.

[127] C. Celma, J.A. Allue, J. Prunonosa, C. Peraire, R. Obach, Simultaneous Determination of Paracetamol and Chlorpheniramine in Human Plasma by Liquid Chromatography-Tandem Mass Spectrometry, Journal of Chromatography A. 870 (2000) 77-86.

[128] L.S. Jensen, J. Valentine, R.W. Milne, A.M. Evans, The Quantification of Paracetamol, Paracetamol Glucuronide and Paracetamol Sulphate in Plasma and Urine Using A Single High-performance Liquid Chromatography Assay, Journal of Pharmaceutical and Biomedical Analysis. 34 (2004) 585-593.

[129] T. Belal, T. Awad, C.R. Clark, Determination of Paracetamol and Tramadol Hydrochloride in Pharmaceutical Mixture Using HPLC and GC-MS, Journal of Chromatographic Science. 47 (2009) 849-854.

[130] H. Lou, H. Yuan, Z. Ruan, B. Jiang, Simultaneous Determination of Paracetamol, Pseudoephedrine, Dextrophan and Chlorpheniramine in Human Plasma by Liquid Chromatography-Tandem Mass Spectrometry, Journal of Chromatography B. 878 (2010) 682-688.

[131] V.Maslarska, J. Tencheva, Simultaneous Determination and Validation of Paracetamol and Codeine Phosphate in Pharmaceutical Preparation by RP-HPLC, International Journal of Pharmacy and Pharmaceutical Sciences. 5 (2013) 417-419.

[132] D. Mane, U. Kulkarni, K. Kulkarni, R. K. Pardeshi, Detection \& Identification of Paracetamol from Biological Material Using HPTLC Combined with Modern Analytical Technique, Journal of Medicinal Chemistry and Drug Discovery. 2 (2016) 689-698.

[133] C.C. Acta, B. Press, L.P. Hackett, L.J. Dusci, Determination of Paracetamol in Human Serum, Clinica Chimica Acta. 74 (1977) 187-190.

[134] C. Fernandez, Z. Heger, R. Kizek, T. Ramakrishnappa, Pharmaceutical Electrochemistry : the Electrochemical Oxidation of Paracetamol and Its Voltammetric Sensing in Biological Samples Based on Screen Printed Graphene Electrodes, International Journal of ELECTROCHEMICAL SCIENCE. 10 (2015) 7440-7452.

[135] A.M. Santos, F.C. Vicentini, P.B. Deroco, R.C. Rocha-filho, Square-Wave Voltammetric Determination of Paracetamol and Codeine in Pharmaceutical and $\mathrm{Hu}$ man Body Fluid Samples Using a Cathodically Pretreated Boron-Doped Diamond Electrode, J. Braz. Chem. Soc. 26 (2015) 2159-2168.

[136] R.N. Goyal, V.K. Gupta, M. Oyama, N. Bachheti, Differential Pulse Voltammetric Determination of Paracetamol at Nanogold Modified Indium Tin Oxide Electrode,
Electrochemistry. 7 (2005) 803-807.

[137] A.R. Khaskhelia, J. Fischerb, J. Barek, V. Vyskocil, Sirajuddin, M.I. Bhanger, Differential Pulse Voltammetric Determination of Paracetamol in Tablet and Urine Samples at A Micro-crystalline Natural Graphite-polystyrene Composite Film Modified Electrode, Electrochimica Acta. 101 (2013) 238-242.

[138] P.K. Kalambate, B.J. Sanghavi, S.P. Karna, A.K. Srivastava, Simultaneous Voltammetric Determination of Paracetamol and Domperidone Based on A Graphene/Platinum Nanoparticles/Nafion Composite Modified Glassy Carbon Electrode, Sensors and Actuators B. 213 (2015) 285-294.

[139] Molla Tefera, A. Geto, M. Tessema, S. Admassie, Simultaneous Determination of Caffeine and Paracetamol by Square Wave Voltammetry at Poly(4-amino-3-hydroxynaphthalene Sulfonic Acid)- Modified Glassy Carbon Electrode, Food Chemistry. 210 (2016) 156-162.

[140] H.A.M. Hendawy, A.M. Ibrahim, W.S. Hassan, A. Shalaby, H.M. El-sayed, Voltammetric Method for Simultaneous Determination of Ascorbic Acid, Paracetamol and Guaifenesin Using A Sequential Experimentation Strategy, Microchemical Journal. 145 (2019) 428-434.

[141] S. Zhaoa, W. Bai, H. Yuan, D. Xiao, Detection of Paracetamol by Capillary Electrophoresis with Chemiluminescence Detection, Analytica Chimica Acta. 559 (2006) 195-199.

[142] M. Iranifam, S. Khodaei, M. Saadati, Chemiluminescence Reaction of Graphene Oxide - Luminol - Dissolved Oxygen and Its Application for Determination of Isoniazid and Paracetamol, Microchemical Journal. 146 (2019) 850-855.

[143] A. Özcan, Y. Sahin, A Novel Approach for The Determination of Paracetamol Based on The Reduction of $\mathrm{N}$-acetyl-p-benzoquinoneimine Formed on The Electrochemically Treated Pencil Graphite Electrode, Analytica Chimica Acta. 685 (2011) 9-14.

[144] A.M. Santos, A. Wong, A.A. Almeida, O. FatibelloFilho, Simultaneous Determination of Paracetamol and Ciprofloxacin in Biological Fluid Samples Using A Glassy Carbon Electrode Modified with Graphene Oxide and Nickel Oxide Nanoparticles, Talanta. 174 (2017) 610-618.

[145] H. Wang, S. Zhang, S. Li, J. Qu, Electrochemical Sensor Based on Palladium-Reduced Graphene Oxide Modified with Gold Nanoparticles for Simultaneous Determination of Acetaminophen and 4-Aminophenol, Talanta. 178 (2018) 188-194.

[146] B. Ma, H. Guo, M. Wang, L. Li, X. Jia, H. Chen, R. Xue, W. Yang, Electrocatalysis of Cu-MOF/graphene Composite and Its Sensing Application for Electrochemical 
Simultaneous Determination of Dopamine and Paracetamol, Electrocatalysis. 31 (2019) 1002-1008.

[147] O.W. Lau, S.F. Luk, Y.M. Cheung, Simultaneous Determination of Ascorbic acid, Caffeine and Paracetamol in Drug Formulations by Differential-Pulse Voltammetry Using a Glassy Carbon Electrode, The Analyst. 114 (1989) 1047-1051. doi:10.1039/AN9891401047.

[148] B. Habibi, M. Jahanbakhshi, Abazari Mehri, A Modified Single-walled Carbon Nanotubes/carbon-ceramic Electrode for Simultaneous Voltammetric Determination of Paracetamol and Caffeine, J Iran Chem Soc. 11 (2014) 511-521. 